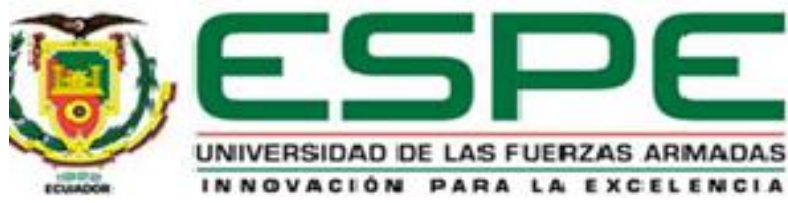

Optimal placement and sizing of distributed generation in a radial distribution system for resilience enhancement against volcanic eruptions

\author{
Saltos Rodríguez, Miguel Angel \\ Departamento de Eléctrica y Electrónica \\ Carrera de Ingeniería en Electromecánica
}

Artículo académico, previo a la obtención del título de Ingeniera en Electromecánica

Ing. Ortiz Villalba, Diego Edmundo MSc.

03 de febrero del 2021 


\title{
OPTIMAL PLACEMENT AND SIZING OF DISTRIBUTED GENERATION IN A RADIAL DISTRIBUTION SYSTEM FOR RESILIENCE ENHANCEMENT AGAINST VOLCANIC ERUPTIONS
}

\author{
M.-Saltos Rodríguez", M.-Aguirre Velasco, A.-Velásquez Lozano, D.-Ortiz Villalba
}

\author{
Department of Electrical and Electronics, Universidad de las Fuerzas Armadas ESPE, Ecuador \\ * [masaltos2, mxaguirre1, amvelasquez1,ddortiz5]@espe.edu.ec
}

\begin{abstract}
Keywords: RESILIENCE, POWER DISTRIBUTION SYSTEMS, DISTRIBUTED GENERATION, VOLCANIC ERUPTION, STOCHASTIC OPTIMIZATION
\end{abstract}

\begin{abstract}
High impact low probability (HILP) events significantly impact the power distribution system (PDS) infrastructure. In this context, resilience is becoming of growing concern worldwide. In this paper, a methodological framework to optimal distributed generation (DG) planning for resilience enhancement in PDS against volcanic eruptions focusing on the lahar occurrence is proposed. The proposed methodology includes the concept of vulnerability curves to determine the unavailability of the PDS elements, the Monte-Carlo simulation method (MCS) to characterize the volcanic lahars and a stochastic optimization problem (SOP). The methodological framework is implemented on the IEEE 37-node test feeder. The results reveal that DG is critical for the resilience enhancement of a PDS against lahars formed by a volcanic eruption. In addition, we present preliminary results of the methodology implemented on a feeder of the San Rafael and Salcedo substations in the concession area of the electricity distribution company ELEPCO S.A. in Cotopaxi-Ecuador, which is vulnerable to lahars that could form in a Cotopaxi volcano eruption located at the northeast of Latacunga city.
\end{abstract}

\section{Introduction}

Power distribution system (PDS) planners have historically designed the electric power infrastructure with reliability standards accounting for the so-called credible outages. However, high-impact low-probability (HILP) events such as natural hazards have even led to chaotic societal situations that go far beyond $\mathrm{N}-1$ or $\mathrm{N}-2$ outages and clearly highlight the need for rethinking current planning practices. In this context, the resilience on PDS is included and defined as the capacity to anticipate, absorb, adapt and recover systems from HILP events. In recent years, resilience enhancement against natural hazards (such as earthquakes, wind storms, wildfires, among others) has been a subject of study. However, there are a limited number of studies that address the planning and operation of resilient PDS against volcanic hazards that can cause significant social and economic damage. In general, tephra falls cause disruption of energy supply caused by insulator flashover due to tephra accumulation, while flow hazards (pyroclastic density currents, lava flows and lahars) are more destructive, causing considerable permanent damage on electrical poles and overhead lines [1]. For instance, according to [2], the economic losses on PDS by Fuego Volcano eruption in 2018 (Guatemala) were estimated at 1.04 MMUSD. Another recent volcanic event was the Cordón Caulle volcano eruption in Chile caused continuous power outages and blackouts that affected about $40 \%$ of the town for at least one month [3].
In this paper, we present a novel methodological framework to determine the optimal placement and sizing of distributed generation (DG) in a PDS for resilience enhancement against large lahars impacting the PDS infrastructure after a volcanic eruption. We also provide a vulnerability curve to estimate the damage states of reinforced concrete electrical poles by lahar impact. The proposal includes a Monte Carlo simulation method (MCS), a stochastic optimization problem (SOP), which includes a linearized AC optimal power flow (AC-OPF) considering a ZIP load model due to the large number of diverse load components in a PDS and their effects caused by voltage regulation, and finally an evaluation of the investment solution from lahar impact to the restoration of the system using a time-dependent resilience metric system.

\section{Methodology}

The proposed methodological framework is illustrated in Fig. 1 and contains four main stages that are explained in detail below.

\subsection{Input Data}

2.1.1 PDS: To evaluate the unavailability of PDS elements, the PDS is represented as a graph in which $G=\left(\Omega_{B}, \Omega_{L}\right)$, where $\Omega_{B}$ denotes the set of nodes and $\Omega_{L}$ represents the distribution overhead lines. 
2.1.2 Volcanic historic data: The historical data used as input data comprise different speeds, and densities resulting from up-to-date, volcanological information generated and compiled during the last years.

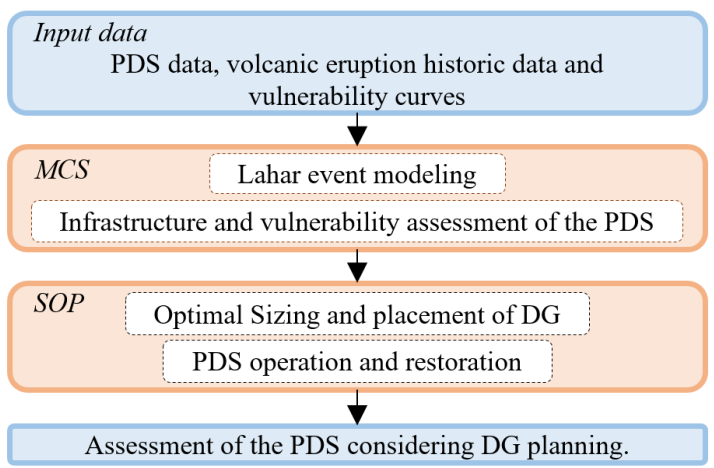

Fig. 1 Proposed methodological framework for resilience enhancement against lahars.

2.1.3 Vulnerability Curves: Vulnerability curves represent the probability of exceeding a given damage state as a function of dynamic pressure (DP) of lahars. The vulnerability curve for reinforced concrete electrical poles is characterized by statistical representations and analysis of large data sets on failure records of system elements obtained from [4] and is illustrated in Fig. 2 .

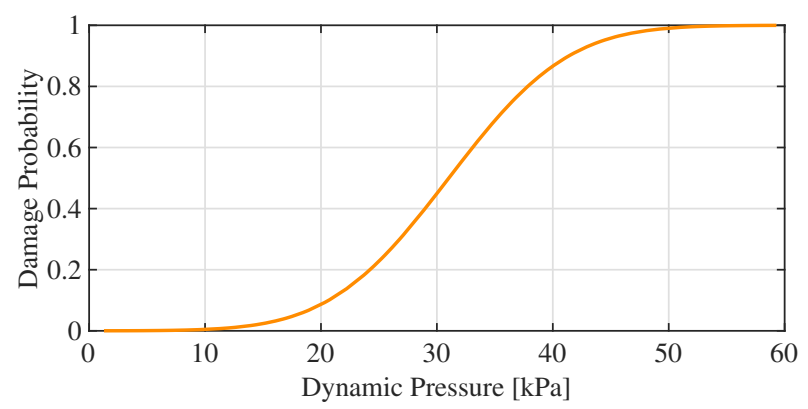

Fig. 2 Vulnerability curve for reinforced concreted electrical poles against lahars.

\subsection{Monte Carlo Simulation}

With the purpose to characterize the lahars, various scenarios are generated using MCS, in which two uncertainty levels are considered (the speed $v_{L}$ and density $\rho_{L}$ ) to determine the DP of lahars. DP is determined using equation (1).

$$
D P=\frac{1}{2} \rho_{L} v_{L}^{2}
$$

Volcanic risk maps are used to determine the elements that could be affected by lahars. The impact of lahars on electrical poles and overhead line are quantified using vulnerability curves (See Fig. 1) and are assessed by making the following assumptions: i) The nodes represent concrete electrical poles and will be unavailable if the damage probability is greater than a probability threshold established. ii) If a node is unavailable, all overhead lines connected with the node are considered unavailable. iii) Recovery times for different unavailable elements of PDS are identified based on their priority levels defined by the PDS operator, considering the sequence of critical loads that must be re-connected to the main grid. Considering this assumption and using graph theory, the input parameters for the optimization problem are established. During the estimated restoration time $(t s)$, the unavailability of nodes $\left(\zeta_{s, t, i}\right)$ and power lines $\left(\psi_{s, t, i j}\right)$ are represented by a binary parameters. In addition, a set of candidate slack nodes $\left(\Omega_{w}\right)$ is determined for the islanding systems formed after a lahar has impacted the PDS infrastructure. These slack nodes are selected considering the load with the highest criticality level. It is worth mentioning that DG models are composed by grid-forming inverters to establishing a slack node in the islanding system after lahar impacts on the PDS. With these type of inverters, DGs will be able to supply the power demand in each islanding power system formed. MCS is implemented using MATLAB R2019a [5].

\subsection{Stochastic Optimization Problem}

Once the scenarios have been defined using the MCS, a SOP is formulated. The objective function minimizes the investment cost $(I C)$ of DG and the operating cost $(O C)$ during system restoration time $(t s)$ for all scenarios obtained from the MCS. For this research work, only photovoltaic systems (PV) are considered as DG due to their high penetration worldwide. The SOP was solved using FICO XPRESS 8.8.0 software [6]. The problem formulation is detailed in Section 3.

\subsection{Power Distribution System assessment}

The ENS and the Energy Index of Unreliability (EIU) presented in [7] are used to assess the PDS planned considering DG. EIU represents the relation between the ENS and the energy demand during the restoration time estimated. Indeed, if the index is $0 \%$, it represents a null ENS, whereas if the index is $100 \%$, the load was not supplied.

\section{Optimization Problem Formulation}

The objective function (2) minimize the $I C$ (3) for installed capacity of PV systems $\left(P_{i}^{P V, \text { inst }}\right)$ on the buses of the PDS $\left(N_{B}\right)$, where, $c^{P V}$ represents the cost per $\mathrm{kW}$ of PV installed. Moreover, during restoration time $\left(t_{s}\right)$, the objective function minimizes the $O C$ (4) that are subject to the probability occurrence $\left(\pi_{s}\right)$ of each scenario $(s)$ generated by the MCS, cost of ENS $\left(c_{i}^{E N S}\right)$, active ENS $\left(E N S_{s, i, t}^{P}\right)$, cost of active power curtailment from PV $\left(c^{P V, \text { curt }}\right)$, PV active power curtailment $\left(P_{s, i, t}^{P V, \text { curt }}\right)$, cost of active power from main grid $\left(c^{\text {grid }}\right)$ and power supplied by the main grid $\left(P_{s, i, t}^{g r i d}\right)$.

$$
\begin{gathered}
\operatorname{Min}(I C+O C) \\
I C=c^{P V} \sum_{i=1}^{N_{B}} P_{i}^{P V, \text { inst }} \\
O C=\sum_{s=1}^{N} \sum_{i=1}^{N_{B}} \sum_{t=1}^{t_{s}} \pi_{s}\left[c_{i}^{E N S} E N S_{s, i, t}^{P}+\right. \\
\left.c^{P V, \text { curt }} P_{s, i, t}^{P V, \text { curt }}+c^{\text {grid }} P_{s, i, t}^{\text {grid }}\right]
\end{gathered}
$$

The model used in [8] is implemented in our proposed methodological framework. The non-linear equations of the full AC 
load flow model are linearized using Taylor series expansions and piecewise linear (PWL) approximation techniques. The ZIP load model (5) is linearized using expansion of the Taylor series, where, $v_{s, t, i}$ is the voltage magnitude of node and $Z_{i}, I_{i}, P Q_{i}$ represents the impedance, current and power constants parameters, respectively. Equations (6) and (7) represent the active and reactive power balance respectively at each node, where, $i, j$ denotes buses index, $\left(P_{s, i, t}^{\text {grid }}, Q_{s, i, t}^{\text {grid }}\right)$ and $\left(P_{s, i, t}^{P V}, Q_{s, i, t}^{P V}\right)$ represent the active and reactive power from the main grid and PV respectively, the active and reactive power flow of the lines are denoted as $P_{s, t, i j}^{L}, Q_{s, t, i j}^{L}$ respectively, the active and reactive electricity demand are denoted as $P_{i}^{\text {Load }}, Q_{i}^{\text {Load }}$ respectively, the ENS are denoted as $E N S_{s, t, i}^{P}, E N S_{s, t, i}^{Q}$, the $\rho_{i}$ parameter indicates in which node the substation is located, the $\tau_{i}$ parameter enables only load nodes for the DG installation (PQ nodes or slack nodes), and $\psi_{s, t, i j}$ parameter represents the unavailability of power lines, the $\zeta_{s, t, i}$ parameter is included to remove the power demand on the nodes impacted directly by a lahar. The equations applied in [9] are used to define ENS constraints. Constraints (8) and (9) represent the slack nodes, which the voltage magnitude and angle $\theta_{s, t, w}$ must be defined, considering that the DG units connected to these nodes are composed of grid-forming inverters to be able to establish slack nodes. Constraints (8)-(11) represent the change from slack nodes to PQ nodes when the islanding systems are re-connected to the main grid. This is a function of recovery time $\left(t r_{s, w}\right)$.

$$
\begin{aligned}
& Z I P_{i}=Z_{i}\left(2 v_{s, t, i}-1\right)+I_{i} v_{s, t, i}+P Q_{i} \quad i \in \Omega_{B} \\
& \rho_{i} P_{s, i, t}^{g r i d}+\tau_{i} P_{s, i, t}^{P V}+\sum_{j \in \Omega_{B}}^{j \neq i} \psi_{s, t, i j} P_{s, t, i j}^{L}= \\
& \zeta_{s, t, i} P_{s, t, i}^{L O A D} Z I P_{i}-E N S_{s, t, i}^{P} \quad i \in \Omega_{B}, i j \in \Omega_{L} \\
& \rho_{i} Q_{s, i, t}^{g r i d}+\tau_{i} Q_{s, i, t}^{P V}+\sum_{j \in \Omega_{B}}^{j \neq i} \psi_{s, t, i j} Q_{s, t, i j}^{L}= \\
& \zeta_{s, t, i} Q_{s, t, i}^{L O A D} Z I P_{i}-E N S_{s, t, i}^{Q} \quad i \in \Omega_{B}, i j \in \Omega_{L} \\
& \theta_{s, t, w}=0 \quad \forall w \in \Omega_{w}, t<t r_{s, w} \\
& v_{s, t, w}=1 \quad \forall w \in \Omega_{w}, t<t r_{s, w} \\
& -\frac{\pi}{2} \leq \theta_{s, t, w} \leq \frac{\pi}{2} \quad \forall w \in \Omega_{w}, t \geq t r_{s, w} \\
& v^{\text {min }} \leq v_{s, t, w} \leq v^{\text {max }} \quad \forall w \in \Omega_{w}, t \geq t r_{s, w}
\end{aligned}
$$

The expected active power injection from a PV system is expressed by the equations used in [10]. Constraint (12) denotes the active power output limits of PV systems, where, $\eta^{i n v}$ represents the inverter efficiency. According to [11], a reasonable increase in ratings to provide reactive power support can be $10 \%$ of the inverter size. In this way, constraint (13) represents the reactive output limits of PV systems. The total installed capacity limits of the PV system in each available node after a volcanic eruption is denoted by constraint (14), and (15) denotes the budget constraint.

$$
\begin{array}{ll}
0 \leq P_{s, t, i}^{P V} \leq P_{i}^{P V, \text { inst }} \eta^{i n v} & i \in \Omega_{B} \\
0 \leq Q_{s, t, i}^{P V} \leq 0.4582 P_{i}^{P V, \text { inst }} \eta^{i n v} & i \in \Omega_{B} \\
0 \leq P_{s, t, i}^{P V, \text { inst }} \leq P^{P V, \text { max }} \zeta^{s, t, i} & i \in \Omega_{B} \\
c^{P V} \sum_{i=1}^{N_{B}} P_{i}^{P V, \text { inst }} \leq \text { Budget } &
\end{array}
$$

\section{Case Study and Results}

To validate the efficiency of the proposed methodology, the IEEE 37-node test feeder [12] is used, in addition, our proposal is implemented on the feeders of the San Rafael and Salcedo substations located in Cotopaxi-Ecuador. It is worth mentioning that for solve the SOP, daily irradiance curves for winter and summer are considered. Moreover, it is assumed that the volcanic eruption might occur at different hours of the day (6:00, 14:00, and 22:00 hours) to include different solar irradiance levels. The maximum installed capacity in each node is limited to $300 \mathrm{~kW}$ and the cost per $\mathrm{kW}$ installed of PV system is considered at $1200 \mathrm{USD} / \mathrm{kW}$ [13].

\subsection{IEEE 37-node test feeder}

4.1.1 Test System: The power system has 36 branches and spot loads. The loads are characterized using representative residential, commercial, and industrial daily load curves obtained from [14], and the ENS costs for each load type are established depending on their priority level. In this mode, industrial loads are prioritized over commercial loads and commercial loads over residential loads. In addition, priority levels are assigned to recover the different unavailable elements of the PDS to ensure critical system load recovery. The estimated complete restoration time $(t s)$ is defined at 12 hours. Moreover, the optimization problem includes a budget constraint established as 1.5 MMUSD.

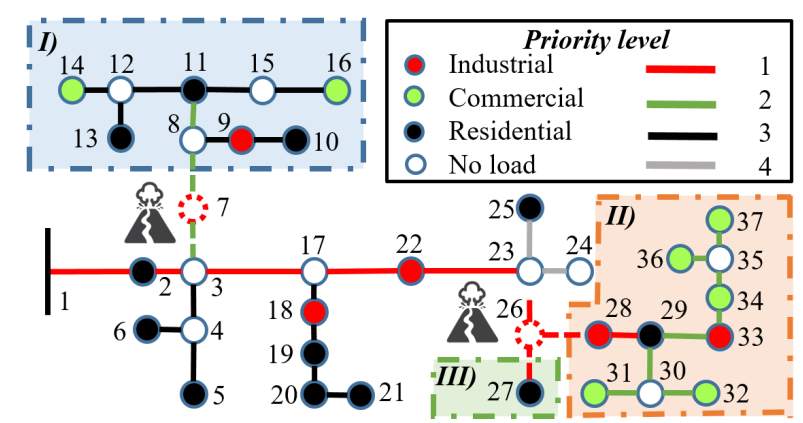

Fig. 3 IEEE 37-node test feeder one-line diagram considering possible islanding systems, lahar impacts, loads types and priority levels.

4.1.2 Lahar modeling: Lahar modeling considers the densities range for hyperconcentrated flows from [15], and the speed results of the two-dimensional modeling of lahars in the Villarica volcano developed in [16]. It is assumed that the affected PDS is located $15 \mathrm{~km}$ from the crater volcano, and nodes 7 and 26 are impacted by a lahar, thus, three possible islanding systems are identified. The islanding recovery time $\left(t r_{s, w}\right)$ for the 
I) islanding system is defined at 9 hours, and the recovery time for the II) and III) islanding system is defined at 4 hours. The one-line diagram of the PDS is shown in Fig. 3

4.1.3 Numerical results: The results of the optimal IC for the placement and sizing of PV systems for resilience enhancement is about 0.8 MMUSD, where DG is installed as slack on node 9 $(145 \mathrm{~kW})$ and node $28(300 \mathrm{~kW})$, and is installed as PQ on node $29(232 \mathrm{~kW})$. As can be seen in Fig. 4, the EIU of the system when DG is not considered is about $22 \%$ and $30 \%$ for the I) and III) islanding system, respectively. The index is improved when the PV systems are installed, as can be seen in Fig. 5. As it was mentioned before, the index is improved as a function of the priority levels of loads.Therefore, for the industrial load installed in node 9, the index is reduced from $30 \%$ to $16 \%$; for the commercial load installed in node 14 , the index is reduced from $30 \%$ to around $18 \%$, and finally for the residential loads installed in nodes 10, 11 and 13 it is reduced from $30 \%$ to $27 \%$ (see Fig. 5).

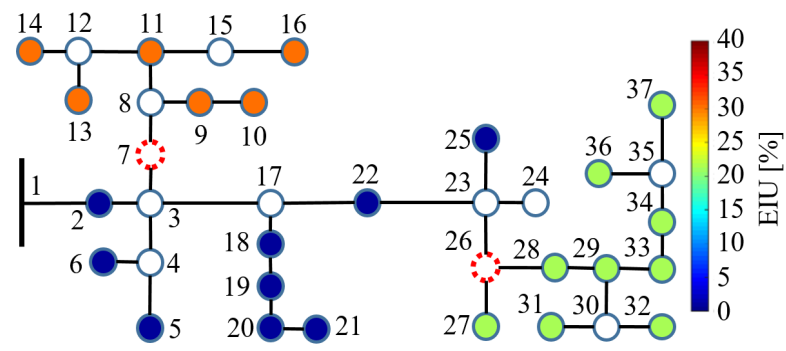

Fig. 4. Energy index of unreliability of actual PDS.

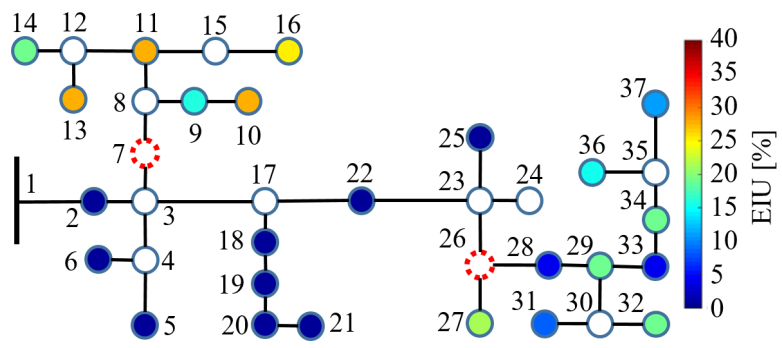

Fig. 5. Energy index of unreliability of PDS considering DG.

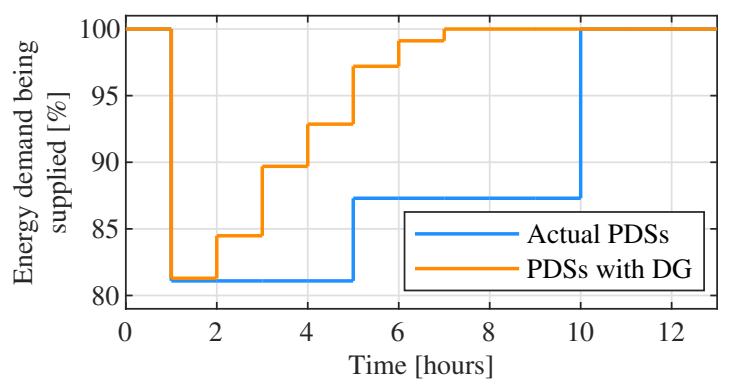

Fig. 6 Evolution of hourly serviceability (i.e. hourly capacity to supply energy demand).

To evaluate the effectiveness of the proposed methodology, the percentage of the energy demand that is supplied is calculated. It is considered the expected case in which Node 7 is unavailable and the volcanic eruption occurs at 6 a.m. in the summer season. In this case, as can be seen in Fig. 6, the percentage to drop instantly after the impact of the lahar on the PDS (hour 1 ) is $81 \%$ for the actual PDS as well as for the PDS considering PV systems. However, during the day, since the solar resource increases, the percentage improves to $93 \%$ at 4 hours for the PDS considering PV systems, while in the actual PDS it remains constant at $81 \%$. Moreover, the total recovery time for the PDS with DG is 6 hours against 9 hours in the actual PDS. The PDS energy demand being supplied, vary since the active power injection depends on the solar resource available at the time of the day in which the volcanic eruption occurs; however, it is possible to reduce the ENS from 1,188 $\mathrm{kWh}$ to $473 \mathrm{kWh}$ during the restoration time.

\subsection{San Rafael and Salcedo feeders}

4.2.1 Test System: The data required to model the San Rafael and Salcedo PDSs was obtained from the geoportal of the ELEPCO utility available at [17]. It is worth mentioning that the electric distance method was used to reduce the feeder nodes; thus, the Salcedo and San Rafael feeders are represented with a total of 136 nodes. Critical loads (Hospitals, Community health centers, Emergency shelters, Industries) were identified according to the Cotopaxi volcano hazard map of the National Secretary for Risk Management available at [18].

4.2.2 Lahar modeling: To characterize the lahars of the Cotopaxi volcano, speed and density data obtained from models based on 1877 historical eruption [19], [20] were used. The one-line diagram of the San Rafael and Salcedo PDSs and the lahar formed by Cotopaxi volcano eruption are shown in Fig. 7

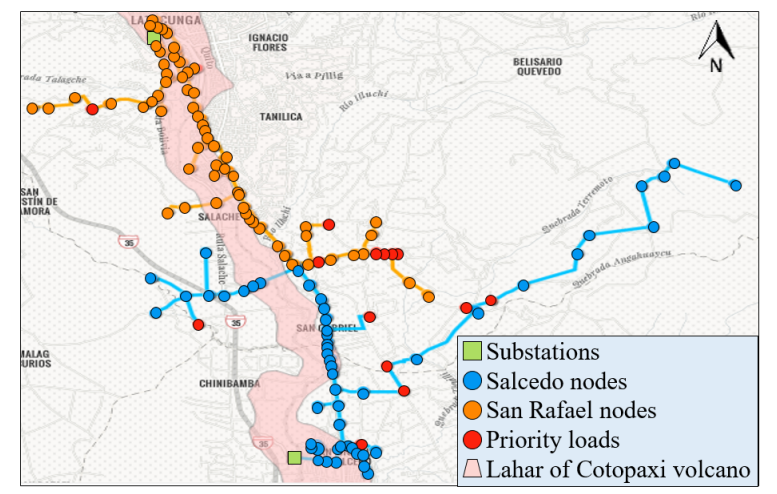

Fig. 7 San Rafael and Salcedo feeders one-line diagram considering lahar impacts and critical loads.

4.2.3 Numerical results: The preliminary results of the optimal placement and sizing of PV systems to resilience enhancement and the average EIU obtained from all scenarios generated during the 12 hours are shown in Fig. 8. The results reveal that the EIU is reduced from $100 \%$ to around $55 \%$ when the PV systems are installed, for all critical loads identified of the Salcedo and San Rafael PDSs and in some loads nodes neighboring of priority loads are reduced from $100 \%$ to around $80 \%$. These EIU results show that the planned DG is able to improve the resilience of the system by focusing primarily on supply energy demand to critical loads. 
Fig. 9 shows the energy demand that is supplied for the case in which the eruption occurs at 6:00 a.m. (1 hour), where it can be seen that the DG planned can supply up to $50 \%$ of the energy demand at the peak of the solar resource at 12:00 p.m. ( 7 hours). Although the energy demand varies depending on the available solar resource, the ENS in the estimated simulation horizon of the San Rafael and Salcedo PDSs is reduced from $41 \mathrm{MWh}$ to $27 \mathrm{MWh}$ when PV systems are considered.

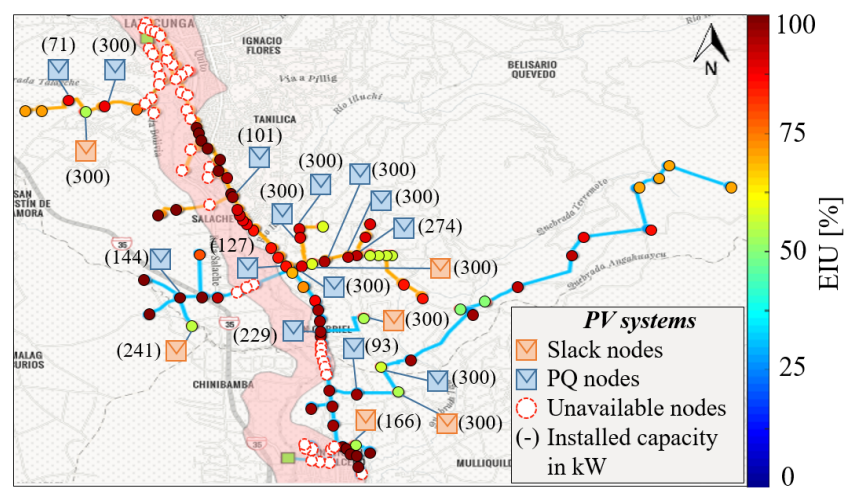

Fig. 8 Energy index of unreliability of Salcedo and San Rafael PDSs considering DG with an IC of 6 MMUSD.

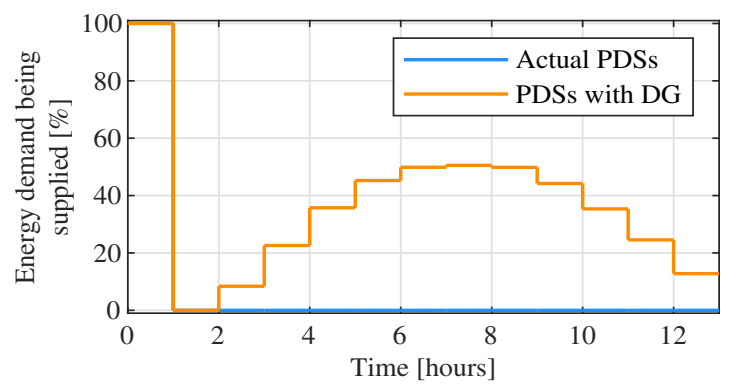

Fig. 9 Evolution of hourly serviceability (i.e. hourly capacity to supply energy demand).

\section{Conclusion}

In this paper, a novel methodology for optimal sizing and placement of DG for resilience enhancement of the PDS against lahars is presented. MCS is implemented to characterize the lahars. The DP is used in the vulnerability curves to determine the unavailability of the power distribution system components. A SOP is proposed for determining the optimal placement and sizing of DG. Also, DG includes the grid-forming power inverters to supply the power demand in each islanding power system formed by impacts of lahars on PDS. The model includes a linearized AC-OPF and ZIP load model. The methodological framework is applied on the IEEE 37-node test feeder and San Rafael and Salcedo feeders located in Cotopaxi-Ecuador. For San Rafael and Salcedo feeders, the EIU on critical loads is reduced from $100 \%$ to $55 \%$ and for IEEE 37-node test feeder, the EIU is reduced from $30 \%$ to $16 \%$. These EIU results show that the proposed methodology is able to obtain the appropriate size and placement of DG for resilience enhancement of PDS against lahars, emphasizing the supply of energy to critical loads such as emergency shelters, community health centers, among others, which are vital against the socio-economic damage that the lahars migth cause.

\section{Acknowledgements}

The authors would like to thank to "Academic Partner Program" (APP) of FICO Xpress Optimization Suite.

\section{References}

[1] G. Wilson, T. Wilson, N. Deligne, and J. Cole, "Volcanic hazard impacts to critical infrastructure: A review," Journal of Volcanology and Geothermal Research, vol. 286, pp. 148-182, 2014.

[2] World Bank, CEPAL, and PNUD, "Evaluación de daños y pérdidas del volcán de fuego," tech. rep., The World Bank, 2018.

[3] M. Elissondo, V. Baumann, C. Bonadonna, M. Pistolesi, R. Cioni, A. Bertagnini, S. Biasse, J.-C. Herrero, and R. Gonzalez, "Chronology and impact of the 2011 cordón caulle eruption, chile," Natural Hazards and Earth System Sciences, vol. 16, no. 3, pp. 675-704, 2016.

[4] G. A. Valentine, "Damage to structures by pyroclastic flows and surges, inferred from nuclear weapons effects," Journal of Volcanology and Geothermal Research, vol. 87, no. 1-4, pp. 117-140, 1998.

[5] "Matlab avaliable: https://www.mathworks.com/products," Sept. 2020.

[6] "Fico xpress optimization suite avaliable: http://www.fico.com/en/products/," Sept. 2020.

[7] A. Poulos, S. Espinoza, J. de la Llera, and H. Rudnick, "Seismic risk assessment of spatially distributed electric power systems," in 16th World Conf. on Earthquake Eng., Santiago, pp. 1949-3029, 2017.

[8] M. Javadi and T. Amraee, "Economic dispatch: A mixed-integer linear model for thermal generating units," in 2018 IEEE International Conference on Environment and Electrical Engineering and 2018 IEEE Industrial and Commercial Power Systems Europe (EEEIC/I\&CPS Europe), pp. 1-5, IEEE, 2018.

[9] H. Mehrjerdi and R. Hemmati, "Modeling and optimal scheduling of battery energy storage systems in electric power distribution networks," Journal of Cleaner Production, vol. 234, pp. 810-821, 2019.

[10] O. Gandhi, C. D. Rodríguez-Gallegos, W. Zhang, D. Srinivasan, and T. Reindl, "Economic and technical analysis of reactive power provision from distributed energy resources in microgrids," Applied energy, vol. 210, pp. 827-841, 2018.

[11] A. Marinopoulos, F. Papandrea, M. Reza, S. Norrga, F. Spertino, and R. Napoli, "Grid integration aspects of large solar pv installations: Lvrt capability and reactive power/voltage support requirements," in 2011 IEEE Trondheim PowerTech, pp. 1-8, IEEE, 2011.

[12] "IEEE PES AMPS DSAS test feeder working group avaliable: https://site.ieee.org/pes-testfeeders/resources/," Sept. 2020.

[13] T. Winarko, N. Hariyanto, F. S. Rahman, M. Watanabe, and Y. Mitani, "Cost-benefit analysis of pv penetration and its impact on the frequency stability: Case study of the south-central kalimantan system," in 2019 IEEE Innovative Smart Grid Technologies-Asia (ISGT Asia), pp. 1700-1705, IEEE, 2019

[14] J. A. Jardini, C. M. Tahan, M. Gouvea, S. U. Ahn, and F. Figueiredo, "Daily load profiles for residential, commercial and industrial low voltage consumers," IEEE Transactions on power delivery, vol. 15, no. 1, pp. 375-380, 2000.

[15] J. E. Costa, "Rheologic, geomorphic and sedimentologic differentiation of water floods, hyperconcentrated flows and debris flows," Flood geomorphology, pp. 113-122, 1988.

[16] D. A. Navarro Morales, "Modelación bidimensional de lahares en el volcán villarrica, chile," 2017.

[17] "Elepco geoportal avaliable:https://gis-sigde.maps.arcgis.com/apps/w ebappviewer/index.html?id=aa01636ecf6448cf82bd2dae559a63c0," Nov. 2020.

[18] "Secretaria nacional de gestion de riesgos avaliable: https://www.gestionderiesgos.gob.ec/wp-contentuploads201508cotop axi-pdf/," Nov. 2020.

[19] P. Vera, P. Ortega, E. Casa, J. Santamaría, and X. Hidalgo, "Numerical model and maps by primary lahars in southern drainage of cotopaxi volcano," Revista Politécnica, vol. 43, no. 1, pp. 61-72, 2019.

[20] P. Mothes and J. Vallance, "Lahars at cotopaxi and tungurahua volcanoes," Ecuador: Highlights from Stratigraphy and Observational Records and Related Downstream Hazards, 2014. 